Abstracta Iranica Abstracta Iranica

Revue bibliographique pour le domaine irano-aryen

Volume 30 | 2010

Comptes rendus des publications de 2007

Nush-i Jan. The Major Buildings of the Median
Settlement. London / Leuven, The British Institute
of Persian Studies / Peeters, 2007, 242 p., 64 Pl.

Rémy Boucharlat

(2) OpenEdition

Journals

Édition électronique

URL : http://journals.openedition.org/abstractairanica/37692

DOI : 10.4000/abstractairanica.37692

ISSN : 1961-960X

Éditeur :

CNRS (UMR 7528 Mondes iraniens et indiens), Éditions de l'IFRI

Édition imprimée

Date de publication : 8 avril 2010

ISSN : 0240-8910

Référence électronique

Rémy Boucharlat, « Nush-i Jan. The Major Buildings of the Median Settlement. London / Leuven, The British Institute of Persian Studies / Peeters, 2007, 242 p., 64 PI. », Abstracta Iranica [En ligne], Volume 30 | 2010, document 93, mis en ligne le 08 avril 2010, consulté le 03 octobre 2020. URL : http:// journals.openedition.org/abstractairanica/37692; DOI : https://doi.org/10.4000/abstractairanica. 37692

Ce document a été généré automatiquement le 3 octobre 2020.

Tous droits réservés 


\title{
Nush-i Jan. The Major Buildings of the Median Settlement. London / Leuven, The British Institute of Persian Studies / Peeters, 2007, 242 p., 64 Pl.
}

\author{
Rémy Boucharlat
}

1 Publication très attendue des cinq campagnes de fouilles, entre 1967 et 1977, sur le tappeh Nush-i Jan, province de Hamadan, le site qui serait emblématique de la culture mède, de la fin du VIII ${ }^{e}$ et du $\mathrm{VII}^{\mathrm{e}} \mathrm{s}$. av. J.-C. jusqu'à l'époque achéménide. Dans ce volume, ce sont les données architecturales, la stratigraphie et la reconstruction de l'histoire du site qui sont détaillées ; les objets ont déjà été publiés par J. Curtis en 1984 et la poterie attend encore.

2 Après une histoire des fouilles et un résumé des rapports annuels, publiés naguère, de façon assez détaillée, dans la revue Iran, les AA. reprennent un par un les monuments, tous exceptionnels par l'originalité de leur plan et par leur état de conservation: Central Temple, le plus remarquable mais aussi le plus problématique, Old Western Building, Fort, Columned Hall et d'autres structures moins individualisées. Tout cela était en grande partie connue par les rapports, mais ils sont ici discutés plus en détail dans des chapitres spécifiques, puis leur plan et des détails d'architecture sont comparés à ceux des monuments contemporains de l'Ouest iranien et d'autres régions. Le chapitre de conclusions propose la reconstitution de la séquence architecturale. C'est dans les réflexions et les discussions sur l'architecture, accompagnées de nombreux plans et reconstitutions, que l'ouvrage apporte le plus de données inédites et ouvre des pistes. Quant à la fonction de chaque bâtiment, en particulier celle des deux temples, les AA. ne s'avancent pas, à l'exception du fort, pour lequel les différentes hypothèses de reconstitutions du plan de l'étage induit des fonctions différentes (stockage, militaire ou résidentielle). Pour le plus connu des bâtiments, il est heureux que « Fire temple » soit définitivement remplacé par «Central Temple» qui, à défaut d'être précis, n'induit pas une fonction précisée (le problème du mazdéisme ou 
zoroastrisme des Mèdes !). Reste la lancinante question « mède ». Le complexe de Nushi Jan, œuvre en définitive modeste, est-il représentatif de ce que pouvait entreprendre un chef ou prince local, pour en faire une résidence avec une chapelle ou au contraire pour ériger un temple entouré des bâtiments nécessaires à son fonctionnement? Les AA. n'en discutent guère. Dans quel contexte politique est-il édifié ? Ils proposent de placer la durée de fonctionnement au moment où le pouvoir mède est morcelé, avant la mainmise assyrienne sur la région, domination qui durerait ensuite jusqu'à la chute de Ninive en 612. Cette domination assyrienne et le type de structure politique sur laquelle elle pèse sont elles-mêmes des questions très débattues, comme l'a montré l'ouvrage récent, Continuity of Empires(?) (cf. Abs. Ir. 26, c.r. n¹17).

INDEX

Thèmes : 3.2.2. Pré-Achéménides et Achéménides

\section{AUTEURS}

RÉMY BOUCHARLAT

CNRS - Lyon 